\title{
Correction to: Oxygen Transport to Tissue XL
}

Oliver Thews, Joseph C. LaManna, and David K. Harrison

\section{Correction to:}

O. Thews et al. (eds.), Oxygen Transport to Tissue XL, Advances in Experimental Medicine and Biology 1072, https://doi.org/10.1007/978-3-319-91287-5

The chapters "Changes in Cytochrome-C-Oxidase Account for Changes in Attenuation of NearInfrared Light in the Healthy Infant Brain" and "A Fibreless Multiwavelength NIRS System for Imaging Localised Changes in Cerebral Oxidised Cytochrome C Oxidase" are made as open access as per the author's request in this revised version of the book.

The updated online version of these chapters can be found at https://doi.org/10.1007/978-3-319-91287-5_2

https://doi.org/10.1007/978-3-319-91287-5_54

The updated online version of this book can be found at https://doi.org/10.1007/978-3-319-91287-5 